\title{
Listening with your eyes: multimodal approaches to art appreciation in primary school
}

\author{
Ruth Breeze \\ rbreeze@unav.es \\ Instituto Cultura y Sociedad, Universidad de Navarra, Spain
}

\begin{abstract}
Fine arts offer opportunities for multimodal approaches in education. Museums and galleries are now aware of their social role, and provide outreach activities designed to bring an understanding of art to a wider public. Their websites offer educational material for school children, showing how artistic knowledge and sensitivity can be cultivated with young age groups. However, little attention has been paid to such didactic material by discourse analysts interested in multimodality. This paper builds on Swales's (2016) article on the genre of the single image account (SIA), which centres on texts about famous paintings written by experts for a general readership. Here, I focus on SIAs for didactic purposes, examining pedagogical resources on the National Gallery's website. Accessible SIAs are combined with suggestions to enhance primary school pupils' learning through creative activities across a variety of modes. Guidelines are provided for writing SIAs for educational purposes in other contexts.
\end{abstract}

Keywords: primary education, art education, multimodality, genre analysis, discourse analysis, single image analysis

\section{INTRODUCTION}

Over the last thirty years, the role of museums and art galleries in many countries has been transformed, so that we can now talk of their key role in bringing culture to wider audiences and promoting lifelong learning. As far as children are concerned, it is clear that museums and galleries have a special function as educational spaces outside the classroom that offer a rich learning environment (Arbués and Naval 2014). With this in mind, leading art galleries around the world have developed an increasingly diverse range of educational and outreach activities designed to bring the works they house to a larger public, and to promote a deeper understanding of art among different target groups (Tishman et al. 2007). As a result, many art galleries have devised educational programmes of activities for children of different ages, including hands-on workshops (Brooklyn Museum 2018), special guided tours for different target groups, or invitations to respond in visual form to the works of art on display (National Gallery 2018). Outside the English-speaking world such adaptations were generally less common, 
possibly for budgetary reasons, but there are signs that this is changing (Fontal Merillas 2009). Most national and regional governments now acknowledge that investment in national heritage is an important goal, and within this, that it is important to promote an understanding of this legacy among the younger generation. For this reason, it is useful to look at the educational strategies adopted in countries like the USA and the UK, which have a longer tradition of bringing culture to a wider audience. This may help institutions in other countries to develop resources along similar lines, either by adapting them for use in local languages, or by devising activities and materials in English for an international audience, or for local schools involved in Content and Language Integrated Learning (Breeze and García Laborda 2016). One of the simplest and least expensive educational strategies to emulate and implement is the preparation of material based on specific artists or individual works of art, adjusted for different age groups. Such material can be used by schools to prepare their visits, or as an aid when studying a particular topic. If it is appropriately adapted to the age groups in question, it can help children learn to experience and appreciate art (Harris and Zucker 2016), and might also act as a stimulus for creative responses of different kinds, thus involving the principle of learning-by-doing (Martikainen 2017).

One such resource is provided in the National Gallery, London, as part of its ongoing educational outreach programme (National Gallery 2018). It consists of sets of notes for primary school teachers, each of which has an explanation of one painting, accompanied by other information (such as background details about the artist's life, his patrons, or the subjects of the painting), and in most cases, ideas for educational activities designed to help children respond to the painting, or encourage them to develop their own creative skills. These resources are linked to the "Take one picture" project that the Gallery has carried out for many years in collaboration with primary schools. Each year, a particular picture from the National Gallery is chosen, and the Gallery provides educational material and short courses for teachers about it. At the end of each season, the Gallery hosts an exhibition showing some of the work that schoolchildren have produced in response to the painting chosen. This programme has several advantages for our present purposes: the National Gallery provides a considerable volume of material designed specifically for primary school teachers, this is always focused on a single work of art, and it is expressly intended to be used by the teachers both to 
develop their pupils' appreciation of art and to foster their creativity. In this paper, my aim is to explore how these "Notes for Teachers" materialise these aims discursively, and to relate this to the bibliography on art education and museum pedagogy, in the hope that it will be interesting for theorists, but also useful for those involved in art education elsewhere.

In this paper, my main approach is discourse analytical, informed by genre theory. Genres serve typical socially recognised communicative purposes, and are in some sense conventionalised (Bhatia 2004). Genres provide a window onto professional practices, and onto the values and epistemology of particular disciplinary communities. By finding out what is stable, or at least frequent, in particular genres, we can learn more about the community that produced them, how they think and how they communicate. Within this, in the concrete case at hand, it is striking that from the perspective of applied linguistics, relatively little attention has been paid to the area of educational and popularising discourses about the visual arts. Despite the intense interest in multimodality and text-image interplay that has developed over the last thirty years (Bateman 2014), most work in the educational field has centred on how picture books create meaning through convergent or complementary semiotic modes (Nicolajeva and Scott 2001, Salisbury and Styles 2012), or how textbooks, infographics or websites exploit intermodal effects (Unsworth 2006). Little research is available that explicitly deals with the way the written mode deals with the visual one, or how language is used to talk about (rather than with or alongside) pictures.

One honourable exception to this is Swales's ground-breaking paper "Configuring image and context: writing 'about' pictures" (2016), which examines one-page accounts of single masterpieces intended for educated adult readers. In this paper, I build on Swales's analysis in two ways: first, by examining texts about art written for primary school teachers, in the knowledge that they are likely to incorporate aspects that may help these readers to arouse children's interest in art; and second, by looking at the practical suggestions available alongside most of these texts, which propose classroom activities and project work to stimulate children's creativity in a variety of media. I will then use this analysis to build a heuristic that could be useful for anyone who needs to write popular educational material to accompany works of art. 


\section{THEORETICAL BACKGROUND}

Works of art in museums and galleries are almost invariably accompanied by written accounts, whether in the form of labels or brief explanations, or in longer formats such as press releases, exhibition catalogues, popular art books and critical analyses. To these, we must add websites and audioguides, which also provide abundant information in different modes. Within this, the single image analysis (SIA) provides a central focus for analysis, since this is a genre found across many of these different publications, and one which in some sense holds the key to art appreciation and education. As Swales (2016) notes, writing about pictures involves first "reading" the picture, and then sequencing the description of the image itself with discussion of any relevant aspects of the context (subject, artist, period, movement, etc.). Although the twofold aim of description and discussion might seem to lend itself to some kind of general-specific macrostructure (in this case, realised in terms of first context, then description), or perhaps a specific-general structure (starting from the image and moving to a commentary encompassing aspects of its background), this does not seem to be usual among art writers. As Swales (2016) shows, what seems to be typical is a kind of "dialectical tacking" (Geertz 1980: 103) between the image, on the one hand, and the background, on the other. Regarding move structure, Swales's own analysis of the SIA identifies this zigzagging between image and background as perhaps the characteristic hallmark of art writing for a general public. In the alternation between image and context, most of Swales's examples seemed to set out from the context, and then to intersperse description of the image with discussion of different aspects of background, but the amount of text dedicated to each, and the length of each "turn", varied considerably from one text to another.

Beyond this, Swales also analyses five other features that he found to be typical of the SIAs in his corpus. These are:

○ comparisons (with other works, or with other artists, styles or periods);

a relative scarcity of intertextual references (i.e. to the writings of other critics or art historians); 
○ complex epistemic patterning, in which speculation is prominent and in which the writer offers "contested (or at least contestable) interpretations of the art objects as well as speculations about the artists and the factors that may have led to the production and construction of their works";

○ frequent use of brackets, to introduce information such as important dates, the whereabouts of paintings, and explanations of materials or techniques;

- positive evaluative language, used to bring out particular qualities of the painting or painter.

In this paper, I will use the general principles of genre analysis (Bhatia 2004, Swales 1990), and the previous work by Swales (2016) to build a description of the SIAs intended for primary school teachers. From the general principles of genre analysis (Swales 1990, Bhatia 2004), it would be expected that these texts will bear some kind of family resemblance to the SIAs analysed in Swales (2016), but that their slightly different communicative purpose will condition their content and structure in different ways. My analysis is complemented with an overview of the different types of activity proposed with a view to enhancing children's experience of art. In the last section, I will provide a heuristic intended to guide writers who need to produce texts about art for educational purposes, based on my observations and analysis.

\section{TEXTS AND METHOD}

My study focuses on 25 sets of "Notes for Primary Teachers", published in the “Teachers' notes" section of the National Gallery website (National Gallery 2018). The Notes had all been prepared for the "Take one picture" scheme that has been running annually since 1995. Notes centring on an entire exhibition, rather than a single image, were excluded from this study. In each case, a single picture from the collection was selected, Notes were prepared, and schoolchildren from all over the country were invited to submit examples of how a class or year group used this particular painting to inspire creative learning. The children's work was then exhibited by the Gallery in the popular "Take one picture" exhibition. 
All of the Notes included in the present study focused on a single image, and 17 were principally pictures of human subjects, while there were five landscapes, two seascapes and one still life. The Notes were downloaded from the website and read carefully, in order to note structural organisation and any other features that they had in common. They were then re-read and coded, and illustrative examples of text selected for each of the main features identified.

\section{GENRE FEATURES}

Each of the Notes consists of a SIA of variable length (generally around 2000 words, but sometimes much shorter), accompanied by the image of the painting itself, sometimes with one or two other images, such as close-up shots of details within the painting, or other paintings using a comparable technique or subject. After the main text, most of the Notes include a list of activities that could be used with primary school pupils, sometimes graded according to age or curricular objectives.

The text itself is often subdivided by means of headings such as "About the artist", "About the painting", "About the subject". However, the Notes vary greatly: in some cases, the writer has preferred to include a single section with the title "About the painting", while in others original headings are inserted, such as "Artistic licence" or "The end of an era".

Although some of the aspects identified by Swales (2016) were also found here, certain features are prominent in the Notes that do not appear in his analysis. We might speculate that some of these, at least, are related to the fact that these texts are written for a specific target: primary school teachers who are going to use the picture with their class. 


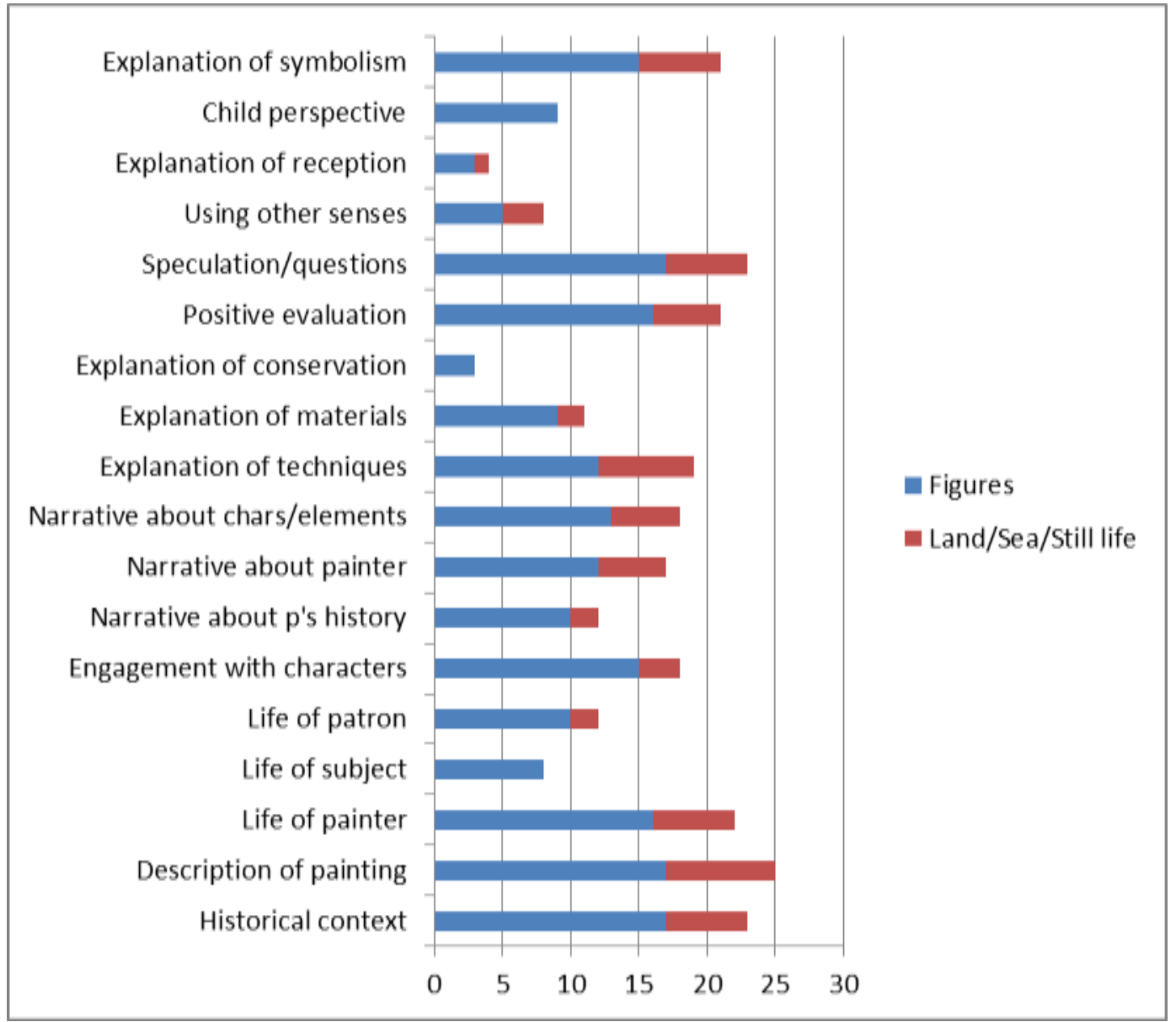

Graph 1. Features included in Notes on paintings of human figures (blue) and landscapes/seascapes/stilllifes (red).

In what follows, I shall discuss some of the more prominent features identified in most of the Notes.

\section{IV.1. Tacking between image and context}

Like the SIAs analysed by Swales, these texts interweave descriptions of the painting with explanations about the personal, historical and artistic background. The following example from the notes about "The hay wain" by John Constable serve to illustrate this back-and-forth movement, which seems to take the reader skilfully in and out of the painting, emulating the way a guide might point to features of the picture and interlace these observations with explanations of different kinds. In the example, I have italicised references to the image: 
(1) Before Constable was born his parents lived in the mill house and afterwards the family continued to live in the Suffolk countryside - the setting for this painting. Constable drew much of his initial inspiration for scenes such as this one from memories of the childhood he had spent in the area. The wisps of smoke curling from the chimney of the house, and the woman beside it, drawing water from the river, give the scene a harmonious, domesticated atmosphere. In the background, in the yellow and green fields, dappled with sunlight, we can see (.....) The cloudy, wind-swept sky would seem to indicate the possibility of rain and certainly evokes the English summertime weather. Constable actually made many of the cloud studies for this painting on Hampstead Heath in London. (Notes to Constable's "The hay wain”)

This free-flowing approach to textual organisation is most pronounced in those sets of Notes which do not have internal subheadings. In others, where the text is subdivided into sections with titles like "About the painting", "About the subject", etc., the organisation is more constrained, but even here the tendency to zigzag is perceptible. For example, in the notes on Turner's "The fighting Temeraire", a section on background accomplishes seamless moves from context to image, as in the following example:

(2) The development of steam power was recognised at the time as enormously important, but as with any new technology, responses ranged from the wildly enthusiastic to the deeply pessimistic. These diverse reactions in a time of change are reflected in The Fighting Temeraire, where Turner exaggerates the stark contrast between the two vessels, which stand for the old order and the new. As the sun sets on the horizon to the right, the new moon rises in the sky. (Notes to Turner's “The fighting Temeraire ${ }^{i \prime}$ )

As this example illustrates, the descriptions provided in the notes are rarely just descriptions, in the sense that they have a didactic purpose - to draw our attention to particular aspects of the painting and bring out their significance. When the writer tells us that the sun sets on the right as the new moon rises, he/she is not simply providing a routine description of the painting: he/she is drawing our attention to features that we might otherwise not have seen, and bringing out the relevance of these in the light of the background he/she has just explained. The written text largely follows the script of a guided tour, in which the guide/writer points to aspects of interest within the painting and relates these to external issues (themes, symbolism, artist, subject). 
Sometimes, the description of the picture has to be more explicit than a guide would be, in terms of what goes where, as the text has to perform the role of the pointing finger to show where the points of interest lie, and also has to bring out the importance of visual aspects (such as colour or line) that might not need to be indicated so explicitly with an audience standing nearby:

(3) There is story-telling in the picture, but we notice the setting first: the early morning sky, the sun (...). Next we may take in the bustle of the port (...). We may have to look quite closely to spot the Queen. Claude helps us to do this through the composition of the picture. He leads our eyes to the group of people on the steps on the right: they are at an intersection of a line of perspective (the step) and the strong vertical of the far left column of the palace. The queen is marked out in the group by the bold colours of her clothes: a pinkish-red tunic, a royal blue cloak and a golden crown. (Notes to Claude's "Seaport with the embarkation of the Queen of Shebaii")

The "tacking" noted by Swales (2016: 25) can thus be related to the didactic function of teaching people how to look (Tishman et al. 2007: 61-62): as we follow the text, we can experience the process of slowing down, looking, pausing and looking again that is so important in the development of our powers of observation. As Fontal Merillas explains (2009: 84), one of the challenges in art education is to teach strategies to develop receptivity, to guide people so that they can feel their way into a work of art. The recursive describing and explaining encapsulated in the Notes is a textual representation of this expert process of pointing, sharing and bringing out the wealth of meaning within each picture for the novice observer.

As Graph 1 shows, the Notes also contained some other recurring themes. These are explained below, with examples where appropriate.

\section{IV.2. Explanation of historical background}

One feature which is prominent in the examples that Swales (2016) uses, but which he does not analyse in any depth, is the presentation of historical background. In the Notes, historical information is present in most cases, and tends to be pitched at a popular level, bringing out direct connections with the picture: 
(4) The 1760s saw the beginning of the Industrial Revolution which went on to dramatically affect the lives of all British people. Wright produced many paintings of industrial environments with strong contrasts of light and shadow, such as blacksmiths' forges, glass blowing houses and blast furnaces. (Notes to Wright's “An experiment on a bird in the air pump iii”")

Background is also typically provided in the form of explanations of terminology used in the title or description of the picture:

(5) The parading figures in Rubens' composition depict a Roman 'triumph'. A triumphal procession was the greatest honour that could be given to a Roman general and was usually awarded to celebrate a great military campaign or victory. (Notes to Rubens" "A Roman triumph ${ }^{\text {iv }}$, )

In general, we can assume that the person writing the Notes assumes little knowledge on the part of the reader, or at least, that he/she wishes to make the information as clear, explicit and straightforward as possible for teachers who are going to use the painting with primary school children.

\section{IV.3. Appeal to human interest}

Perhaps with the primary school target audience in mind, the writers of the Notes often try to engage human interest in the people represented in the picture. This is represented in Graph 1 as engagement with characters, but also within the various types of narrative that appear in the Notes. Intuitively the appeal to human interest would seem to promote the forging of a personal connection, so that observers learn to relate more deeply to the image (Tishman et al. 2007: 64-65):

(6) The organ's sound presumably has inspired the caged bullfinch to sing, which in turn has provoked the predatory cat to leap hopefully up the back of the boy's chair. The two girls seem unaware of this small drama, while baby Thomas, rusk in hand, has eyes only for the cherries held out by his elder sister. (Notes to Hogarth's "The Graham children ")

The Notes also encourage readers to take an interest in the artist and his life: 
(7) In 1630, at the age of 53, Rubens married again. To everyone's surprise he did not marry into the nobility, but chose Helene Fourment, the 16-year-old daughter of a respectable merchant family. Rubens was clearly bowled over by his new wife with whom he has five children, and she figures in numerous portraits, including a version of 'The Judgement of Paris' in which she appears as Venus. (Notes to Rubens' “An autumn landscape with a view of Het Steen ${ }^{\mathrm{vi}}$ ”)

Within the cultivation of human interest, the child perspective has a particular importance. This perspective appears in various ways, including the explanations of life in the painter's time:

(8) Boys would be apprenticed around the age of 14 and would need to train for some years. As well as learning to draw and paint they needed to master various practical and craft skills. Once trained, they could join the painters' guild and set up as independent masters with their own assistants and apprentices and hope to gain prestigious commissions. (Notes to Pintoricchio's "Penelope with the suitors ${ }^{\mathrm{vii}}$ ")

But the account of the people in the painting, if these are children, also tends to be a special focus of interest:

(9) The young girl on the right of the painting holds a hoop and stick. The hoop for such a toy might be made of metal or wood, and the object of the game was to keep the hoop upright while rolling it along the ground with the stick. Skilled players could do this for lengthy amounts of time and some performed tricks. (Notes to Renoir's "The umbrellas viii ")

(10) The painting has a jolly atmosphere with the three children making a lot of noise and enjoying themselves. And it's painted in a realistic way, so you can imagine being in this room with them, singing along and hearing their laughter. (Notes to Molenaer's "Two boys and a girl making music ${ }^{\mathrm{xi}}$ ”)

\section{IV.4. Use of embedded narrative}

One aspect that is particularly prominent in these SIAs, presumably because of their didactic purpose and young wider audience, is narrative, which again can involve either telling the story depicted, or recounting incidents from the life of the painter, the commissioning of the painting, or its subsequent reception (see Human interest, above, and Graph 1). 
(11) Odysseus is the figure coming through the door disguised by the Goddess Athena as an old beggar with his staff. On the wall above Penelope's head are his bow and quiver of arrows. Penelope sets up an archery contest saying she will marry the suitor who can string the bow and win the contest. No one is strong enough to string the bow except Odysseus himself. He reveals his identity and the couple are reunited. (Notes to Pintoricchio's "Penelope with the suitors")

This narrativising tendency also extends to the story of objects in the painting:

(12) This drinking-horn, made in 1565, still exists and is on show at the Amsterdam Museum in Amsterdam. It belonged to the Saint Sebastian Archers who were the likely patrons of the painting. On special occasions the officers would gather to feast and the horn would be filled with wine and ceremoniously passed among them. (Notes to Kalf's "Still life with the drinking horn of the St Sebastian's archers' guild, lobster and glasses ${ }^{\mathrm{x}}$ ")

However, it should also be noted that the Notes are intended for people working within a rather broad age range, which means that the narratives offered are not geared to a particular age group. It seems that the teachers in each case would be responsible for adapting the contents and language of the story to their students' level and interests.

\section{5. Positive evaluative language}

In his analysis, Swales (2016) pointed to evaluative language as one of the features that seems to be present in essence in SIAs, but which is subject to individual (or possibly cultural) variation. Here, since the writers are anonymous, it would be difficult to trace any cultural effects. There is certainly evaluative language in almost all the Notes, but it is administered very sparsely and soberly. Thus we are told that "The stonemason's yard” is “often regarded as Canaletto's masterpiece”, while Turner is “one of Britain's best-known landscape painters".

A more interesting kind of evaluation tends to be delivered through the wording of the descriptions themselves: we read that Pintoricchio "cleverly gives us a sense of the whole narrative" by showing different episodes of Odysseus' story in the foreground and background, while Turner's sailing ship is "painted delicately in light tones" before a "glorious sunset". The focus of these SIAs is on observation and response to the image, but there are none of the "enthused evaluations" reported by Swales (2016: 32), 
and objective observation is generally preferred to emotional evocations of aesthetic effects.

\section{IV.6. Using the five senses}

With the target audience in mind, some of the Notes draw on senses other than sight in order to suggest ways of presenting the picture. The most usual strategy is through the evocation of sound, as in example (10) cited above describing Molenaer's picture, or example (13) below:

(13) The picture is not only full of riotous colour and movement but also full of imaginable sounds: you can almost hear the growls of the animals; the horns and pipes being blown by musicians; the pounding of footsteps. (Notes to Rubens's “A Roman triumph")

Other senses are occasionally engaged in these SIAs, particularly touch, in the context of temperature:

(14) How cold is it? Cold enough for ice that is safe for skating - and for a large horse to walk on it! (Notes to Beerstraaten's "The castle of Muiden in winter xiii ")

But interestingly, multisensory response is encouraged in the activities listed at the end of the Notes much more frequently than it is used in the actual SIA (see Graph 1).

\section{IV.7. Explanation of symbolism}

A further didactic strategy that is prominent in these Notes is the special emphasis on explaining the symbolic aspects of many of the paintings. Some of these glosses are rather straightforward, like the following one, which boils down to "dogs can symbolise faithfulness":

(15) In art, dogs are often used to symbolise marital fidelity, so perhaps Veronese was making a comment by including them in his painting. (Notes to Veronese, "The family of Darius before Alexander ${ }^{\text {xii } ") ~}$ 
However, in other cases the writer attempts a more elaborate explanation involving several layers of meaning, including aspects of technological, social and cultural history that shed light on specific aspects of the painting:

(16) Black was an expensive dye at this time and was only worn by wealthy people: it also signified Melancholy and indicated that the wearer had introspective intellectual qualities, which were much admired at the time. (Notes to Holbein's "The ambassadors")

\section{IV.8. Asking questions and speculating}

As Graph 1 shows, one feature that many of the Notes have in common is their use of questions or speculative suggestions, which overlaps with what Swales (2016: 28-29) calls "contested interpretations". Although in his texts this function was frequently associated with epistemic elements, most particularly hedging and various hearsay/mindsay evidentials, in the Notes it is mainly represented by direct questions:

(17) Next to this jar stands an imposing figure robed in red, quite different to all the others present. With his hand outstretched towards us he is the only person to look out of the painting and make eye-contact with us. Is he asking us a question or perhaps inviting us to take a closer look? (Notes on Wright's “An experiment on a bird in the air pump”)

In most cases, these questions have no answer, but sometimes an answer is proposed, usually an answer in line with the age of the prospective audience and their presumed response to the picture:

(18) Something, or somebody, has caught the attention of the little girl on the right, and the woman on the left. What, or whom, are they looking at? Perhaps they are looking at us? It is almost as if we are standing in the picture with them. (Notes on Renoir's "The umbrellas")

In a few cases, a more sophisticated analysis is presented, which seems to address the teachers rather than their (primary age) students. In this case, more complex hedging devices ("tend to believe") and uncertainty is stressed ("we cannot be sure") in order to spark curiosity: 
(19) But which man in the painting is Alexander? (...) Art historians tend to believe that the man in crimson is Alexander, because he is more central to the composition, and is the more conspicuously dressed of the two, but we cannot be sure. The possibility of confusion is necessary if we are to understand the queen mother's mistake. Veronese has left us with a mystery, and after nearly 500 years, we are still not sure of the answer. (Notes to Veronese, "The family of Darius before Alexander")

\section{IV.9. Explanation of symbolism}

A further aspect that may be particularly prominent because of the educational function of these texts is their insistence on aspects of technique and material.

(20) Seurat had a special interest in optics and the science of colour, particularly the writings of the chemist Michel-Eugène Chevreul. (...) Chevreul stated that complementary colours, opposites on the colour wheel, enhanced each other when placed side-by-side. The use of complementary contrasts can be seen everywhere in the picture, from small brushstrokes to larger areas of colour. For example, in the predominantly green riverbank, there are strokes of the complementary colours pink and green, and also some bright yellow and violet, and orange and blue. (Notes to Seurat, "Bathers at Asnières ${ }^{\text {xiv } ") ~}$

This emphasis on topics such as primary colours here certainly reflects the primary school curriculum. However, other explanations of material and technique are more sophisticated. In the Notes on Wright's painting "An experiment on a bird in the air pump", the question of dark and light is emphasised, and brought into a wider art historical context:

(21) Wright used screens in his studio to control the light and here he has displayed a dazzling arrangement of light and deep shadow. The thin layers of dark glaze (paint mixed with varnish to give a translucent glow) are placed next to more thickly opaque highlights. Using extremes of light and shade in a painting to create a sense of drama is called chiaroscuro and is most usually associated with Caravaggio and his followers. (Notes to Wright's "An experiment on a bird in the air pump")

Moreover, the text goes on to explain that this is more frequently found in religious paintings of the era, and provides two images illustrating uses of chiaroscuro in other paintings to complement the reader's understanding of its function. 
In other cases, the explanation deals with the concrete material basis of paint and canvas. Again, description is complemented by interpretation, in which the work of art in question is compared with other works or styles.

(22) The painting uses oil paint applied to paper. This gives it a smooth finish, with no surface texture. The three pieces of paper were stuck together, and the joins are quite visible, especially at the left. They were then mounted on canvas. This is an unconventional approach, but one which is typical of Degas. The three sections make it resemble both a triptych, a three-panel Christian altarpiece, and three-part Japanese woodblock prints. (Notes to Dégas's "Beach scene $\left.^{\mathrm{ix},}\right)$

Other Notes concerning technique bring out idiosyncratic aspects of the painting in question which might be interesting to a young audience, or which illustrate something significant about the material, technique or style of the picture:

(23) Also visible are lots of pentimenti. Literally meaning 'changes of minds', these alterations or corrections have become increasingly visible as the oil paints have become translucent with the passage of time. For example the lynx in the bottom right hand corner appears to have an extra leg and initially the young man in white had a larger head of hair. (Notes to Rubens's "A Roman triumph")

\section{HEURISTIC FOR WRITING EDUCATIONAL SINGLE IMAGE ACCOUNTS}

This section is intended as a guide for teachers or museum staff who need to create educational material for use with young children. In the following section (VI), there is a compilation of activity types that could be used to accompany the explanation of the work of art.

Imagine yourself standing in front of the picture, explaining it to a group of children:

- What overall impression does this picture make?

- How might children use the five senses to respond to this picture?

- What themes or aspects do you want to talk about in more detail?

- How are these themes or details associated with?: 
○ shared human feelings (particularly those accessible to children)

○ narratives (myths, legends, historical events)

○ymbols (conventional or original)

- Are the composition, techniques or materials used interesting?

- Do you want to talk about any relevant aspects of the painter's life?

- Are there any mysteries or unanswered questions associated with the painting, its subject or its artist?

When you are writing your SIA, remember that you need to use words to "point" to particular aspects of the painting that you want to discuss. You can use expressions like these to begin your description:

- As we can see in the image...

- As the picture shows...

- Scenes/figures/landscapes like this...

You can then relate these descriptions to background and context by using phrases like:

- These colours are associated with...

- This image evokes...

- The objects here symbolise...

- This type of figure is typical of the...

You can go back from discussing context to pointing out instantiations in the painting by using phrases like:

- ... is reflected/represented/echoed in the painting, where...

- ... can be seen in the composition of the picture, which...

Remember, you don't need to give definitive explanations about everything. It might be more interesting to open up discussion so that children can try to think of answers: 
- What do you think this person is thinking?

- Why do you think the artist chose this colour/animal/background?

\section{SAMPLE ACTIVITIES}

In this section, I provide an overview of different types of activities found in the Notes, without reference to specific paintings, age groups or curricular goals, and going from the more general response activities to the more complex or specific ones.

○ Learning to look at the picture more carefully: working together in pairs, one pupil describes the picture and another draws, then they swap roles; using the website to create crops of the picture and then working together in groups to piece together the whole picture.

- Responding to the people in the painting on a personal level: what do you think the people are saying/thinking/feeling? If you could ask one of the people one question, what would it be?

○ Multimodal response to the painting: 'listen' with your eyes, what can you hear? What is the noisiest thing in the painting? If you could jump into the painting, what would you see, hear, smell, touch? Who or what might live in there? What music would go with this painting? If the picture were an advertisement, what could you use it to advertise?

- Responding to the subject of the painting by reproducing one part of it, or drawing/painting something along similar lines, i.e. a full length painting of oneself with a classmate, a tableau of a scene from mythology, a group portrait, a skyscape, a "modern" still life, a representation of the same scene in a different season.

- Response to the subject, theme or mood of the painting by creating works in different media, including visual arts, i.e. sculpture and film, but also music or imaginative writing (stories, poems, descriptions).

- Using part of the picture as a basis for a design: i.e. the floor in the painting is made of patterned tiles, so design your own patterned tiles. 
- Experimenting with materials used by artists in the past, e.g. egg tempera.

○ Researching and responding to artistic styles: research the elements of Rococo style and design something inspired by it.

- Exploring connections with other curricular areas: find out the French words for the objects in the painting. Make a geographical enquiry into volcanoes. On a modern map, trace Odysseus's journey from Troy to the island of Ithaca. Investigate how other religions and culture participate in similar parades and celebrations today. Investigate dragon symbolism in other cultures.

\section{CONCLUSIONS}

We have seen that these Notes share some of the basic features identified by Swales (2016), most particularly the characteristic zigzagging between image descriptions and context explanations. In this, it is interesting to think of the role of the writer as emulating that of the museum guide, but also as reflecting a stable tendency among art writers to oscillate between the visual and the verbal, or between showing and telling. In Baxendall's classic words (1979: 455), “one of the art historian's specific faculties is to find words to indicate the character of shapes, colours and organizations of them. But these words are not so much descriptive as demonstrative". Unlike other multimodal genres, where the different semiotic modes may generate convergent, complementary or divergent messages (Bateman 2014) and language-image interactions have to be decoded by users (Unsworth 2006), in this genre the written text is expressly dedicated to revealing and explicating the image. Here, the writer uses words explicitly to create a shared vision of the picture, and to guide the reader's eyes into and around the world within the frame.

Despite the underlying commonality that these Notes share with Swales's SIAs, certain new features are prominent here. We might speculate that some of these, at least, are related to the fact that these texts are written for a specific double target: primary school teachers (immediate readers) who are going to use the picture with their class (target audience). As Fontal Merillas explains (2009: 84), one of the challenges in art education is to facilitate the development of receptivity and artistic sensibility. Teachers therefore 
need to deploy a range of strategies to encourage their pupils to share a sensation, feeling or idea, and thus to help them feel their way into a work of art (Harris and Zucker 2016). For this reason, aspects such as human interest (in the people represented in the picture, or in the artist and his life) are often highlighted in these SIAs, and narrative (again, telling the story depicted or incidents from the life of the painter) has an important role in many of the texts. In some of the Notes, multimodal responses based on hearing/smelling/feeling propose additional points of access to the painting, stimulating the imagination and encouraging children to experience the picture more fully (Harris and Zucker 2016). The Notes thus gently propose a series of pedagogical strategies for the teachers to use with their pupils. The activities suggested at the end of the Notes build on this by prompting multimodal responses of the kind recommended in recent art pedagogy (Martikainen 2017). Finally, one discursive feature that many of the notes have in common is their use of questions or speculative suggestions, which overlaps with what Swales calls "contested interpretations", but which is generally expressed here through direct questions. Unlike the hedged speculations reported by Swales, these do not provide a glimpse of academic controversy, but rather convey a certain cognitive challenge which children may find stimulating.

\footnotetext{
Notes

i "The fighting Temeraire", by Joseph Turner.

ii "Seaport with the embarkation of the Queen of Sheba", by Claude Lorrain.

iii "An experiment on a bird in the air pump", by Joseph Wright.

iv "A Roman triumph", by Peter Paul Rubens.

v "The Graham children", by William Hogarth.

vi "An autumn landscape with a view of Het Steen", by Peter Paul Rubens.

vii "Penelope with the suitors", by Pintoricchio (Bernardino di Betto).

viii "The umbrellas", by Pierre-August Renoir.

ix "Beach scene", by Edgar Dégas.

$x$ "Still life with the drinking horn of the St Sebastian's archers' guild, lobster and glasses", by Willem Kalf.

xi "Two boys and a girl making music", by Jan Miense Molenaer.

xii "The family of Darius before Alexander", by Paolo Veronese.

xiii "The castle of Muiden in winter", by Jan Abrahamsz Beerstraaten.

xiv "Bathers at Asnières", by Georges-Pierre Seurat,
}

All Notes are available on the webpage:

https://www.nationalgallery.org.uk/learning/teachers-and-schools/teachers-notes 


\section{REFERENCES}

Arbués, E. and Naval, C. 2014. "Museums as educational social spaces". Estudios sobre Educación, 27, 133-151.

Bateman, J. 2014. Text and image. A critical introduction to the visual/verbal divide. London: Routledge.

Baxendall, M. 1979. "The language of art history”. New Literary History, 10, 453-465.

Bhatia, V. K. 2004. Worlds of written discourse. London: Continuum.

Breeze, R. and García Laborda, J. 2016. "Issues in teacher education for bilingual schools". Estudios sobre Educación, 31, 9-12.

Brooklyn Museum. 2018. Hands on art. 19 March 2018. https://www.brooklynmuseum.org/education/youth-and-families/hands_on_art

Fontal Merillas, O. 2009. "Los museos de arte: un campo emergente de investigación e innovación para la enseñanza del arte". Revista Electrónica Interuniversitaria para la Formación del Profesorado, 12 (4), 75-88.

Geertz, C. 1980. Negara. The theater state in nineteenth-century Bali. Princeton, NJ: Princeton University Press.

Harris, B. and Zucker, S. 2016. "Making the absent present: the imperative of teaching art history”. Art History Pedagogy and Practice, 1 (1). 19 March 2018. http://academicworks.cuny.edu/ahpp/vol1/iss $1 / 4$

Martikainen, J. 2017. "Making pictures as a method of teaching art history". International Journal of Education and the Arts, 18 (19). 19 March 2018. http://www.ijea.org/v18n19/v18n19.pdf

National Gallery. 2018. Take one picture. 19 March 2018. https://www.nationalgallery.org.uk/learning/teachers-and-schools/take-onepicture

Nicolajeva, M. and Scott, C. 2001. How picturebooks work. London: Routledge.

Salisbury, M. and Styles, M. 2012. Children's picturebooks: the art of visual storytelling. London: Lawrence King. 
Sears, E. 2002. “"Reading' images”. In Sears, E. and T. K. Thomas (Eds.) Reading medieval images. Ann Arbor: University of Michigan Press, 1-17.

Swales, J. 1990. Genre analysis. English in academic and research settings. Cambridge: Cambridge University Press.

Swales, J. 2016. “Configuring image and context: writing 'about' pictures". English for Specific Purposes, 41, 22-35.

Swales, J. and Feak, C. 2013. Academic writing for graduate students. Ann Arbor: University of Michigan Press.

Tishman, S., McKinney, A. and Straughn, C. 2007. Study center learning: An investigation of the educational power and potential of the Harvard University Art Museums Study Center. Boston MA: Harvard Project Zero.

Unsworth, L. 2006. "Towards a metalanguage for multiliteracies education: describing the meaning-making resources of language-image interaction". English Teaching Practice and Critique, 5 (1), 55-76.

Received: 10 April 2018

Accepted: 23 July 2018

Cite this article as:

Breeze, Ruth 2018. "Listening with your eyes: multimodal approaches to art appreciation in primary school". Language Value 10 (1), 45-67 Jaume I University ePress: Castelló, Spain. http://www.e-revistes.uji.es/languagevalue.

DOI: http://dx.doi.org/10.6035/LanguageV.2018.10.4

ISSN 1989-7103

Articles are copyrighted by their respective authors 